\title{
Bocaviren als häufige Ursache einer Pneumonie bei Kindern
}

Don $\mathrm{M}$ et al. Serologically Verified Human Bocavirus Pneumonia in Children.

Pediatr Pulmonol. 2010;45:120-126

\section{Hintergrund}

Das humane Bocavirus (HBoV) ist ein neu identifiziertes Parvovirus, das häufig bei Kindern mit akuten Atemwegs- und Magendarminfektionen zu finden ist. Seine Bedeutung für die kindliche Pneumonie ist bisher unbekannt.

\section{Methodik}

Über einen Zeitraum von 15 Monaten wurden prospektiv 124 Kinder im Alter von einem Monat bis 15 Jahren, die bei Verdacht auf eine Pneumonie in Norditalien stationär aufgenommen worden waren, mithilfe serologischer Antikörpertests untersucht. Dabei wurden 16 verschiedene Mikroorganismen (Streptococcus pneumoniae, Haemophilus influenzae, Moraxella catarrhalis, Mycoplasma pneumoniae, Chlamydia pneumoniae, Simkania negevensis, Respiratory Syncytial Virus (RSV), humaner Metapneumovirus, Influenzaviren A und B, Parainfluenzaviren 1-3, Adenovirus, Cytomegalovirus und $\mathrm{HBoV}$ ) erfasst. 101 Kinder hatten eine radiologisch bestätigte Pneumonie.

\section{Ergebnisse}

Nach RSV-Infektionen, die bei $17 \%$ der Kinder auftraten, war eine HBoV-Infektion die zweithäufigste Ursache (12\%) für die Pneumonie. Sieben Kinder waren ausschließlich mit HBoV infiziert, während fünf Kinder gemischte Infektionen mit anderen Viren oder mit Bakterien aufwiesen. Elfmal wurde die Diagnose durch ein erhöhtes IgM, sechsmal durch einen Anstieg von IgG gestellt.

\section{Schlussfolgerung}

Die Seropositivität für $\mathrm{HBoV}$ steigt altersabhängig und hat mit dem Ende des Vorschulalters fast $100 \%$ erreicht. HBoV sind eine häufige Ursache der Pneumonie bei Kindern.

\section{Kommentar}

Prof. Dr. med. Matthias Griese, München

HBoV sind nach RSV und Rhinoviren die dritthäufigsten Viren, die bei kleinen Kindern mit einer obstruktiven Bronchitis gefunden werden. Bei etwa 70-90\% der Kinder mit akutem Giemen finden sich im Rahmen einer virusinduzierten Atemwegsobstruktion serologische Hinweise auf HBoV. Bei etwa 10-20\% können in diesen Situationen HBoV aus den Atemwegssekreten identifiziert werden. Vorläufige seroepidemiologische Daten deuteten auf die Bedeutung von $\mathrm{HBoV}$ hin, da IgG-Antikörper bei über $90 \%$ der unter Sechsjährigen nachgewiesen werden.

Außerdem wird deutlich, dass entscheidend auf die Methodik und Definition der Infektion geachtet werden muss. Untersuchungen die nur auf dem Nukleinsäurenachweis (PCR) aus Sekreten beruhen und bei denen oft simultan weitere Viren gefunden werden, können die genaue pathogenetische Rolle von HBoV nicht einordnen.

Obgleich RSV-Infekte insbesondere zwischen November und Januar häufig vorkamen, hatte nur ein Kind eine Mischinfektion mit HBoV und RSV. Dies spricht für die unabhängige pathogenetische Bedeutung von HBoV für Pneumonien.

\section{Fazit}

Dies ist die erste Studie, die klare Belege für die Rolle von HBoV bei Pneumonien liefert. Eine vorherige PCR-Untersuchung hatte das Virus bei 3,9\% der kindlichen Pneumonien identifiziert. Alle HBoV-positiven Pneumonien traten bei Kindern unter vier Jahren auf. Eine fast komplette Serokonversion ist bis zum Alter von sechs Jahren erreicht. Inwieweit die Antikörper protektiv wirken oder erneute Infektionen auftreten können, ist noch offen. 